Rogulska Karolina, Strońska Aleksandra, Grzeszczak Konrad. The role of nutrigenetics in diet personalisation. Journal of Education, Health and Sport. 2021;11(8):75-79. eISSN 2391-8306. DOI http://dx.doi.org/10.12775/JEHS.2021.11.08.008 https://apcz.umk.pl/czasopisma/index.php/JEHS/article/view/JEHS.2021.11.08.008 https://zenodo.org/record/5196621

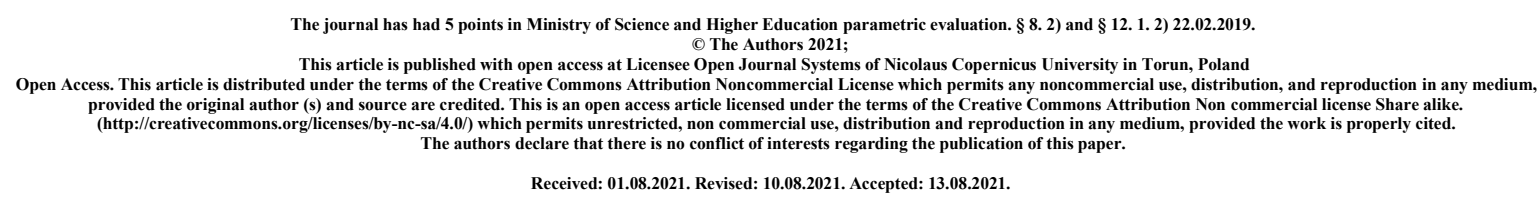

\title{
The role of nutrigenetics in diet personalisation
}

Karolina Rogulska; https://orcid.org/0000-0003-1413-7430; karolina.rogulska@pum.edu.pl; Pomeranian Medical University, Department of Microbiology, Immunology and Laboratory Medicine, Powstańców Wielkopolskich Street 72, 70-111, Szczecin, Poland.

Aleksandra Strońska; https://orcid.org/0000-0001-6564-2141; aa.stronska@gmail.com Department of Pharmacognosy and Natural Medicines, Pomeranian Medical University in Szczecin, Powstańców Wielkopolskich 72, 70-111 Szczecin, Poland.

Konrad Grzeszczak; https://orcid.org/0000-0002-3055-3357;

konrad.grzeszczak@pum.edu.pl; Pomeranian Medical University; Department of Biology and Medical Parasitology; Powstańców Wielkopolskich Street 72, 70-111, Szczecin, Poland.

\begin{abstract}
Nutrigenetics is the field that studies genetic differences in relation to food components. It also examines the risk of food-dependent diseases. The search for genes responsible for disease occurrence is very difficult because the human genome has about 25,000 genes. Association studies are used to identify the relevant genes, and then the presence of polymorphisms is compared with a group of healthy people (control group). Thanks to these tests, it is possible to take an individual approach to the patient and arrange a personalized diet, which results in obtaining the best results. This article focuses on selected diseases including lactase deficiency, celiac disease, phenylketonuria and folate deficiency. In each of these diseases thanks to molecular research, it is possible to detect genetic defects, and then to apply a personalized diet which excludes or provides certain food products. Further development of nutrigenetics in the future will allow even better selection of diets in other disease entities.
\end{abstract}


Key words: nutrigenetics; personalized diet; genetic polymorphism

Human nutrition is a field that is constantly evolving and gaining popularity. Diet is an important aspect of life in terms of both physical and mental health. Many people use the services of dietitians in order to prepare a personalized diet selected for a particular individual and his or her lifestyle. The effects of dieting are mainly attributed to environmental factors, but for a while now scientists have believed that the response to a diet can be genetically determined. Therefore, it seems reasonable to adapt the diet to the person, because it may bring the best results (Konstantinidou et al., 2014). Nutrigenetics is the field that studies genetic differences in relation to food components. It also examines the risk of fooddependent diseases (Corella and Ordovas, 2009). The search for genes responsible for disease occurrence is very difficult because the human genome has about 25,000 genes. Association studies are used to identify the relevant genes, and then the presence of polymorphisms is compared with a group of healthy people (control group) (Virgili and Perozzi, 2008). For nutrigenetic testing, we use either blood or cheek swabs to extract DNA. This is followed by molecular testing by PCR and sequencing (Floris et al., 2020). Thanks to these tests, it is possible to take an individual approach to the patient and arrange a personalized diet, which results in obtaining the best results.

Lactose is the main carbohydrate found in milk. The enzyme that hydrolyzes lactose to glucose and galactose is lactase. It is extremely important during infancy, when milk is the main component of the diet. Later in life, its activity decreases, but expression of the gene coding region for lactase is high in some people. This allows lactose to be breakdown in adulthood. This trait is called LP and occurs in about 35\% of adults (Gerbault et al., 2011)

In recent years, many single nucleotide polymorphisms (SNPs) associated with LP have been discovered. The first to be discovered was $13910^{*} \mathrm{~T}$, followed by G / A-22018, which are not found in the LCT gene or lactase gene but in a neighboring gene - MCM6 (Ennatah et al., 2002). Studies have shown that this change may modify lactase promoter function and may lead to LP (Olds and Sibley, 2003). People who do not have LP show a 
problem breakdown lactose, which results in gastrointestinal symptoms (Swagerty et al., 2002).

Persistent gluten intolerance (celiac disease) is a chronic inflammatory disease of the small intestine (Sollid and Jabri, 2005). It is a disease caused by both environmental and genetic factors. Environmental factors are caused by a fraction of prolamines found in cereal grains - wheat, rye and barley (van Heel and West, 2006). The genetic basis is found in tissue compatibility antigens (HLA). These include the HLA-DQ2 and HLA-DQ8 alleles (Vader et al., 2003). Gluten peptides containing serine or tyrosine can induce an immune response by binding APC (antigen binding cells) to HLA-DQ2 and HLA-DQ8 (Auricchio et al., 2004). Stimulation of the immune response results in proliferation of crypt enterocytes, which causes their hyperplasia (Abadie and Jabri 2014).

Phenylketonuria is an inborn disease involving a defect in metabolism. It is characterized by mutations in the PAH gene - phenylalanine hydroxylase (Blau et al., 2010). This enzyme converts phenylalanine to tyrosine in the presence of molecular oxygen, the cofactor tetrahydrobiopterin (BH4), and iron. Lack of phenylalanine hydroxylase activity results in elevated levels of phenylalanine in the blood, which results in a accumulation of phenylalanine in the brain. Untreated phenylketonuria leads to mental retardation and neurological symptoms such as movement disorders and seizures (Blau 2016).

Folate deficiency caused by insufficient intake of folates manifests itself in reduced concentrations of these compounds in the blood, resulting in increased homocysteine levels (Siaw-Cheok and Esha Das 2015). In addition, elevated homocysteine levels are an increased risk factor for cardiovascular and cerebrovascular disease, and may be a cause of depression or cognitive disorders (Scaglione and Panzavolta 2004). Genetic polymorphisms involving the folic acid pathway are linked to homocysteine metabolism. The C677T variant found in the gene encoding the enzyme that is responsible for folic acid metabolism, methylenetetrahydrofolate reductase (MTHFR), is the main genetic factor affecting folate levels. MTHFR catalyses the conversion reaction of 5,10-methylenetetrahydrofolate to 5methyltetrahydrofolate in an irreversible reaction. This enzyme is important in the context of regulating the amount of bioavailable folic acid during homocysteine remethylation (Hiraoka and Kagawa 2017).

The selection of an appropriate diet for a specific patient is extremely important in the context of diseases with a genetic basis. In each of the examples presented above, thanks to molecular research, it is possible to detect genetic defects, and then to apply a personalized 
diet which excludes or provides certain food products. Further development of nutrigenetics in the future will allow even better selection of diets in other disease entities.

\section{REFERENCES}

1. Abadie V, Jabri B. IL-15: a central regulator of celiac disease immunopathology. Immunol Rev. 2014;260(1):221-234. DOI: 10.1111/imr.12191

2. Auricchio S, Barone MV, Troncone R. Dietary proteins and mechanisms of gastrointestinal diseases: gliadin as a model. J Pediatr Gastroenterol Nutr. 2004;39 Suppl 3:S738-9. DOI: 10.1097/00005176-200406003-00011

3. Blau N, van Spronsen FJ, Levy HL. Phenylketonuria. Lancet. 2010;376(9750):1417-27. DOI: 10.1016/S0140-6736(10)60961-0

4. Blau N. Genetics of Phenylketonuria: Then and Now. Hum Mutat. 2016;37:508515. DOI: $10.1002 /$ humu. 22980

5. Corella D, Ordovas JM. Nutrigenomics in cardiovascular medicine. Circ Cardiovasc Genet. 2009;2(6):637-651. DOI: 10.1161\%2FCIRCGENETICS.109.891366

6. Enattah NS, Sahi T, Savilahti E, Terwilliger JD, Peltonen L, Järvelä I. Identification of a variant associated with adult-type hypolactasia. Nat Genet. 2002;30(2):233-7.

7. Floris M, Cano A, Porru L, et al. Direct-to-Consumer Nutrigenetics Testing: An Overview. Nutrients. 2020;12(2):566. DOI: 10.3390/nu12020566

8. Gerbault P, Liebert A, Itan Y, et al. Evolution of lactase persistence: an example of human niche construction. Philos Trans $R$ Soc Lond B Biol Sci. 2011;366(1566):863-877. DOI: 10.1098/rstb.2010.0268

9. Hiraoka M, Kagawa Y. Genetic polymorphisms and folate status. Congenit Anom (Kyoto). 2017;57(5):142-149. DOI: 10.1111/cga.12232

10. Konstantinidou V, Daimiel L, Ordovás JM. Personalized nutrition and cardiovascular disease prevention: From Framingham to PREDIMED. in Adv Nutr. 2015;6(5):627. DOI: 10.3945\%2Fan.113.005686

11. Olds LC, Sibley E. Lactase persistence DNA variant enhances lactase promoter activity in vitro: functional role as a cis regulatory element. Hum Mol Genet. 2003;12(18):2333-40. DOI: $10.1093 / \mathrm{hmg} / \mathrm{ddg} 244$ 
12. Scaglione F, Panzavolta G. Folate, folic acid and 5-methyltetrahydrofolate are not the same thing. Xenobiotica. 2014;44(5):480-8. DOI: $10.3109 / 00498254.2013 .845705$

13. Siaw-Cheok L, Esha Das G. Methylenetetrahydrofolate reductase (MTHFR) C677T polymorphism: Epidemiology, metabolism and the associated diseases. Eur. J. Med. Genet. 2015;58(1):1-10. DOI: 10.1016/j.ejmg.2014.10.004

14. Sollid LM, Jabri B. Is celiac disease an autoimmune disorder? Curr Opin Immunol. 2005;17(6):595-600.

15. Swagerty DL Jr, Walling AD, Klein RM. Lactose intolerance. Am Fam Physician. 2002;65(9):1845-50. Erratum in: Am Fam Physician. 2003;67(6):1195.

16. Vader W, Stepniak D, Kooy Y, et al. The HLA-DQ2 gene dose effect in celiac disease is directly related to the magnitude and breadth of gluten-specific $\mathrm{T}$ cell responses. Proc Natl Acad Sci U S A. 2003;100(21):12390-12395. DOI: $10.1073 /$ pnas. 2135229100

17. van Heel DA, West J. Recent advances in coeliac disease. Gut 2006;55:1037-1046. DOI: $10.1136 \% 2$ Fgut.2005.075119

18. Virgili F, and Perozzi G. How does Nutrigenomics impact human health?. IUBMB Life, 2008;60:341-344. DOI: 10.1002/iub.85 